\title{
Acute lung injury following lung resection: is one lung anaesthesia to blame?
}

Significant developments in the multiple disciplines of anaesthesia, pharmacology, radiology, and cardiorespiratory physiology have established the foundations for the practice of modern thoracic surgery. The introduction of endobronchial intubation and one lung anaesthesia for thoracic surgery in the 1930 s by Gale and Waters ${ }^{1}$ in the USA and Magill $^{2}$ in the UK enabled the lung on the operated side to be excluded from tidal ventilation, thereby preventing contamination of the contralateral lung by secretions and diminishing the amount of surgical manipulation during the procedure. Together with the introduction of muscle relaxants and techniques of controlled ventilation, facilitated by the advent of double lumen endotracheal tubes, the hazards previously associated with spontaneous ventilation in an open hemithorax were virtually eliminated. At the turn of the century the main indications for thoracic surgery were empyema and tuberculosis. In the post-war period the development of antituberculous chemotherapy, together with the discovery of penicillin in 1945, revolutionised the treatment of infective lung disease and, coupled with the increase in cigarette consumption, infective pathology was superseded by malignancy as the main indication for pulmonary resection.

\section{Complications of contemporary thoracic surgery}

In current practice, preoperative preparation by formal evaluation of pulmonary function ${ }^{34}$ and intensive postoperative care (particularly physiotherapy) are vital in minimising the most frequent postoperative respiratory complications of atelectasis and pneumonia ${ }^{5}$ which may be life threatening in this setting. However, conventional parameters used in preoperative assessment have not been shown to be of predictive value in identifying those patients at risk of developing the potentially fatal complication of - what is termed in the North American literature "postpneumonectomy pulmonary edema" (PPE). ${ }^{6}$

PPE is uncommon and the literature describing its incidence and outcome is sparse. Typically, it presents clinically as acute lung injury following lung resection. Apart from acute respiratory distress, physical examination and signs may be unremarkable in the early stages. The most striking feature is rapidly progressive and refractory arterial hypoxaemia. Radiological changes often lag behind the frequently devastating clinical decline and range from diffuse interstitial infiltration to florid alveolar oedema. To differentiate between PPE and hydrostatic oedema, guidelines suggest that a pulmonary artery occlusion pressure of less than $18 \mathrm{~mm} \mathrm{Hg}$ is required. However, the pulmonary artery occlusion pressure may be falsely low following pneumonectomy ${ }^{7}$ and not accurately representative of pulmonary capillary hydrostatic pressure. Distinguishing PPE from postoperative pneumonia may be difficult as a low grade pyrexia may be apparent in both. An absence of positive blood and sputum cultures favours PPE but is not exclusive and the two may coexist.

The overall incidence of PPE is estimated to be $4-5 \%,{ }^{89}$ although most reports have been isolated cases or small studies. Thus, out of a yearly total of 3315 lung resections for malignancy in the UK (pneumonectomy and lobectomy only), PPE might complicate about 160 cases. ${ }^{10}$
The associated mortality is extremely high and exceeds $80 \%$ in most series. ${ }^{11}$ Statistically significant risk factors such as right sided pneumonectomy and intravenous fluid overload were identified in early studies ${ }^{1213}$ but have received conflicting support in more recent reviews. ${ }^{814}$

In its extreme form PPE follows a clinical and histological course indistinguishable from the acute respiratory distress syndrome (ARDS), ${ }^{11}$ representing one of its many and diverse aetiologies. The diagnosis of ARDS remains one of exclusion, and therapeutic intervention is largely supportive. The pulmonary pathology of ARDS is characterised by increased permeability of the alveolar capillary membrane resulting from diffuse damage to the alveolar capillary unit. Many patients who do not meet the recently defined diagnostic criteria for ARDS may meet those specified simultaneously as defining acute lung injury (ALI). ${ }^{15}$ Of the conditions associated with ALI/ARDS and the many individuals at risk, ${ }^{16}$ only a few develop the full blown syndrome. Far more patients suffer from a lesser degree of lung injury, but recent evidence suggests that even these and those individuals at risk of developing ARDS display signs of a loss of endothelial integrity. ${ }^{17}$ Altered pulmonary endothelial permeability has therefore emerged as the characteristic hallmark of all forms of ALI/ARDS.

\section{Functional significance of PPE}

Endothelial damage and loss of integrity has important functional implications since the endothelium is an important regulatory body in pulmonary and systemic vascular control. ${ }^{1819}$ Endothelium-derived relaxing factor, recently identified as nitric oxide (NO), ${ }^{20}$ is released continuously under resting conditions and has been shown to be an important messenger molecule involved in the physiological regulation of basal vessel tone and tissue blood flow, ${ }^{21}$ ventilation/persusion matching and airway relaxation, ${ }^{22}$ and the immune response. The endothelium has also been shown to modulate the phenomenon of hypoxic pulmonary vasoconstriction (HPV), ${ }^{23-25}$ a unique physiological control mechanism distinguishing the pulmonary from the systemic circulation (which dilates in response to hypoxia). ${ }^{26-28} \mathrm{HPV}$ is an important adaptive mechanism that serves to divert blood away from hypoxic alveoli so that matching of ventilation and perfusion is improved and arterial hypoxaemia minimised. The complex mechanism underlying HPV may be mediated by a critical change in the balance of locally produced vasodilators, in particular NO, and vasoconstrictors such as endothelin. ${ }^{29}$ Significantly, HPV is lost in patients with ALI/ARDS, contributing to an increase in shunt fraction and resulting in refractory hypoxaemia. ${ }^{30}$ It is therefore likely that PPE represents the severe end of a spectrum of ALI, the effects of pulmonary endothelial damage ranging from mild respiratory impairment to the overwhelming pulmonary oedema that characterises ARDS. The incidence and long term significance of milder forms of PPE after thoractomy are not known. At best, mild postoperative lung injury may necessitate a prolonged stay in an expensive critical care or high dependency facility. At worst, it could compromise maximal potential respiratory performance secondary to the effects of the inflammatory insult on 
"healthy" lung tissue previously unaffected by the primary disease process.

The closest approximation to PPE recognised clinically is probably the lung injury that follows surgery involving cardiopulmonary bypass, which is detectable in all such patients and in those undergoing lung transplantation. ${ }^{3132}$ The pathophysiology of these conditions bears close similarities to that of pulmonary resection, in that all these procedures involve collapse and subsequent re-expansion of the lung and therefore a period of relative ischaemia followed by reperfusion. It is probable that all patients undergoing lung resection may suffer a similar acute lung insult, further exacerbated by hyperfusion of residual lung tissue, a difference which may account for the less frequent and less fatal occurrence of a clinically recognisable disorder in the former situations. The lung injury attributable to ischaemia-reperfusion following lung resection may be manifest along a spectrum from low grade, transient, and clinically insignificant to one of frank ARDS/PPE with associated multisystem organ failure and attendant high mortality.

\section{Pathophysiology of PPE}

The pathophysiology of PPE is not fully understood and the underlying mechanisms have not been fully elucidated. The relative importance of increased pulmonary capillary hydrostatic pressure secondary to altered haemodynamics in a restricted pulmonary vascular bed and excessive fluid overload, balanced against a reduction in the compensatory mechanism of lymphatic drainage, is largely undetermined. Although all factors may contribute to some degree, recent experimental and clinical evidence suggest that altered alveolar capillary membrane permeability plays a much more significant part. ${ }^{933}$

Although the exact mechanism of endothelial damage and altered permeability complicating pulmonary surgery is unknown, the phenomenon of ischaemia-reperfusion mediated by reactive oxygen species is implicated. Ischaemia-reperfusion injury is a complex phenomenon, the consquences of which may lead to both local and distant tissue damage. Interruption of the blood supply and therefore oxygenation of a tissue results in anaerobic metabolism and an increased lactic acid conentration causing acidosis and altered enzyme kinetics. Cellular homeostasis is altered resulting in dysfunction, interstitial oedema and, ultimately, cell destruction mediated by depletion of ATP and failure to maintain necessary ionic gradients across cell membranes. ${ }^{34}$ Although reperfusion and the restoration of the blood and oxygen supply is a prerequisite for tissue recovery in order to restore energy supply and remove toxic metabolites, paradoxically reperfusion can result in further local tissue injury and may mediate systemic effects through the return of toxic metabolites to the circulation. ${ }^{35}$ This paradoxical injury has been shown to be influenced by the interaction of endothelially-released factors, reactive oxygen species and neutrophils. ${ }^{36}$

Locally produced endothelial factors affect vascular reactivity, permeability, and neutrophil function. Activation and adhesion of neutrophils occurs with the release of granular proteases and reactive oxygen species and results in local tissue damage mediated by lipid peroxidation of the cell membrane. Evidence suggests that the initial inflammatory event during ischaemia-reperfusion is initiated by non-leucocyte derived reactive oxygen species resulting in subsequent adhesion and activation of neutrophils with alteration to the local microvascular permeability and amplification of reperfusion injury via granule depletion of reactive oxygen species and release of cytotoxic enzymes. ${ }^{37}$ In the isolated rat lung preparation ischaemia- reperfusion injury mediated by reactive oxygen species and their effects on the endothelium in alteration of HPV and increased vascular permeability has been shown to occur. ${ }^{38}$ In the pulmonary reimplantation response to single lung transplantation there is evidence to suggest that the membrane permeability oedema that occurs is related to ischaemia-reperfusion injury to the graft. ${ }^{39}$

In pulmonary surgery involving single lung ventilation ischaemia-reperfusion almost certainly occurs. During one lung anaesthesia relative ischaemia of the ipsilateral lung is followed by re-expansion and reperfusion of the remaining lung tissue following lobectomy, and by hyperperfusion of the contralateral lung following pneumonectomy. It is therefore likely that all patients undergoing pulmonary surgery involving single lung ventilation are subjected to conditons under which the risk of developing lung injury is increased. Factors that determine the degree of endothelial damage produced in any individual patient, and the subsequent effect on the release of endothelially released vasoactive factors, particularly $\mathrm{NO}$, and their influence in modulating HPV, have yet to be determined. Whether NO plays a causative or protective part in the aetiology of lung injury is also not clear. At the molecular level NO may react with reactive oxygen species to produce other powerful and toxic oxidants ${ }^{40}$; conversely, exogenous inhaled NO has been shown to be of therapeutic value in patients with lung injury by selectively dilatating the pulmonary vasculature and improving ventilation/perfusion mismatch and oxygenation. ${ }^{41}$

\section{Conclusion}

Further examination of the parameters of oxidative stress, perioperative changes in the vasoregulatory mechanisms of the pulmonary circulation, and characterisation of the endothelial insult that probably occurs in all patients undergoing lung resection is necessary if the operative conditions under which lung surgery is carried out are to be optimised. Perhaps, then, more insight might be gained into how to improve preservation of lungs for transplantation and how to protect the lung from significant injury following resection.

Correspondence to: Dr T W Evans.

Unit of Critical Care,

National Heart and Lung Institute,

Royal Brompton Hospital,

London SW3 6NP, UK

Department of Thoracic Surgery

Royal Brompton Hospital,

London SW3 6NP, UK

E A WILLIAMS $T$ W EVANS

1 White GMJ. Evolution of endotracheal and endobronchial intubation. $\mathrm{Br}$ F Anaesth 1960;32:235-46.

2 Magill IW. Endotracheal anaesthesia. Reprinted from Proceedings of the Royal Society of Medicine 1929; xxii: 83. Anaesthesia 1978;33:580-6.

Tisi GM. Preoperative evaluation of pulmonary function. Am Rev Respir Dis 1979;119:293-310.

4 Gass GD, Olsen GN. Preoperative pulmonary function testing to predict postoperative morbidity and mortality. Chest 1986;89:127-35.

5 Kirsch MH, Rotman H, Behrendt DM. Complications of pulmonary resection. Ann Thorac Surg 1975;20:215-36.

6 Peters RM. Postpneumonectomy pulmonary edema. Appl Cardiopulmonol Pathophysiol 1989;3:43-51.

7 Wittnich C, Trudel J, Zidulka A, Chiu RC. Misleading "pulmonary wedge pittnich C, Trudel J, Zidulka A, Chiu RC. Misleading "pulmonary wedge
pressure" after pneumonectomy: its importance in postoperative fluid pressure" after pneumonectomy: its imp
therapy. Ann Thorac Surg 1986;42:192-6.

8 Waller DA, Gebeitken C, Saunders NR, Walker DR. Noncardiogenic pulmonary edema complicating lung resection. Ann Thorac Surg 1993; 55:140-3.

9 Shapira OM, Shahian DM. Postpneumonectomy pulmonary edema. Ann Thorac Surg 1993;56:190-5.

10 UK Thoracic Surgical Register, 1992.

11 Turnage WS, Lunn JJ. Postpneumonectomy pulmonary edema. A retrospective analysis of associated variables. Chest 1993;103:1646-50.

12 Zeldin RA, Normandin D, Landwing D, Peters RM. Postpneumonectomy pulmonary edema. F Thorac Cardiovasc Surg 1984;43:323-6.

13 Verherijen-Breemhaar L, Bogaard JM, Van den Berg B, Hilvering C. Postpneumonectomy pulmonary edema. Thorax 1988;43:323-6. 
14 Mathru M, Blakeman BP. Don't drown the "down lung." Chest 1993;103: 1644-5.

15 Bernard GR, Artigas A, Brigham KL, Carlet J, Falke K, Hudson L, et al. The American-European Consensus Conference on ARDS. Am $\mathcal{Y}$ Respir Crit Care Med 1994;149:818-24.

16 Fowler AA, Hamman RF, Good JT, Benson KN, Baird M, Eberle DJ, et al. Adult respiratory distress syndrome: risk with common predispositions. Ann Intern Med 1983;98:593-7.

17 Rocker GM, Pearson D, Wiseman MS, et al. Diagnostic criteria for ARDS time for reappraisal. Lancet 1989;i:120-1.

18 Liu SF, Crawley DG, Barnes PJ, Evans TW. Endothelium-derived relaxing factor inhibits hypoxic pulmonary vasoconstriction in rats. Am Rev Respir Dis 1991;143:32-7.

19 Vanhoutte PM. The endothelium modulator of vascular smooth muscle tone. N Engl f Med 1988;319:512-3.

20 Palmer RMJ, Ferrige AG, Moncada S. Nitric oxide release accounts for the biological activity of endothelium-derived relaxing factor. Nature 1987 327:524-6.

21 Moncada S, Palmer RMJ, Higgs EA. Nitric oxide: physiology, pathophysiology and pharmacology. Pharmacol Rev 1991;43:109-42.

22 Culotta E, Koshland D. NO: molecule of the year. Science 1992;258:1862-5.

23 Liu SF, Dewar A, Crawley DE, Barnes PJ, Evans TW. Effects of tumour necrosis factor on hypoxic pulmonary vasoconstriction and endotheliumdependent relaxation in the blood perfused rat lung. $\mathcal{F}$ Appl Physiol 1992; 72:1044-8.

24 Crawley DG, Zhao L, Giembyzc MA, Liu SF, Barnes PJ, Evans TW. Chronic hypoxia impairs soluble guanate cyclase-mediated pulmonary arterial relaxation in the rat. Am $\mathcal{F}$ Physiol 1992;263:L325-32.

25 Zhao L, Crawley DE, Hughes JMB, Evans TW, Winter RJD. Endothelium derived relaxant factor activity in rat lung during hypoxic pulmonary vascular remodelling. f Appl Physiol 1992;72:1061-5.

26 Staub NC. Site of hypoxic vasoconstriction. Chest 1985;88(Suppl): 24 S-45S

27 Von Euler US, Liljestrand G. Observation on the pulmonary arterial blood pressure in the cat. Acta Physiol Scand 1946;12:301-20.
28 Motley HL, Cournard A, Werko L, Himmelstein A, Dresdale D. The influence of short periods of anoxia upon pulmonary artery pressures in man. Am $\mathcal{f}$ Physiol 1947;150:315-20.

29 Kourembanas S, McQuillan LP, Leung GK, Faller DV. Nitric oxide regulates the expression of vasoconstrictors and growth factors by vascular endothelium under both normoxia and hypoxia. $\mathcal{f}$ Clin Invest 1993;92:99-104.

30 Rounds SIS. Pulmonary vascular control in lung injury. In: Weir EK, Reeves JT, eds. Pulmonary vascular physiology and pathophysiology. Vol. 58 . New JT, eds. Pulmonary vascular physiolog

31 Messent M, Sullivan K, Keogh BF, Morgan CJ, Evans TW. Adult respiratory distress syndrome following cardiopulmonary bypass. Anaesthesia 1992; 47:267-8

32 Hunter DN, Morgan CJ, Yacoub M, Evans TW. Changes in pulmonary vascular permeability after lung transplantation. Chest 1992;102:417-21

33 Mathru M, Blakeman B, Dries D, Kleinman B, Kumar P. Permability pulmonary edema following lung resection. Chest 1990;98:1216-8.

34 McCord JM. Oxygen-derived free radicals in post-ischemic tissue injury. $N$ Engl f Med 1985;312:159-63.

35 Parks DA, Granger DN. Contributions of ischemia and reperfusion to mucosal lesion formation. Am $\mathcal{f}$ Physiol 1986;250:G749-53.

36 Grace PA. Ischaemia-reperfusion injury. Br $\mathcal{F}$ Surg 1994;81:637-47.

37 Seibert AF, Haynes J, Taylor A. Ischaemia-reperfusion injury in the isolated rat lung. Am Rev Respir Dis 1993;147:270-5

38 Messent M, Griffiths MJD, Evans TW. Augmentation of the pulmonary vascular response to hypoxia in ischemic-reperfused lung. Am Rev Respir Dis 1993;147:A931.

39 Sleiman C, Mal H, Fournier M, Duchatelle JP, Icard P, Groussard O, et al. Pulmonary reimplantation response in single-lung transplantation. Eur Respir ₹ 1995;8:5-9.

40 Beckman JS, Beckman TW, Chen JA, Marshall PA, Freeman BA. Apparent hydroxyl production by peroxynitrite: implications for endothelial injury hydroxyl production by peroxynitrite: implications for endothelial injury
from nitric oxide and superoxide. Proc Natl Acad Sci USA 1990;87: from nitric 4 .

41 Rossaint R, Falke KJ, Lopez F, Slama K, Pison U, Zapol WM. Inhaled nitric oxide for the adult respiratory distress syndrome. $N$ Engl $₹ \mathrm{Med}$ 1993;328:399-405. 


\section{LETTER TO THE EDITOR}

\section{Lung disease induced by drug addiction}

In their editorial on the pulmonary consequences of illicit drug use (November 1995; 50:1125-7) Benson and Bentley draw attention to barotrauma as a complication of cocaine inhalation. Pneumothorax, pneumomediastinum, and pneumopericardium have also been described, however, in association with the use of marijuana, ${ }^{12}$ a drug that is more widely used in England and Australia than cocaine. The mechanism of injury is thought to be by coughing while breathholding in inspiration, or by performance of a Valsalva manoeuvre. The latter has been recognised as a cause of spontaneous pneumomediastinum since the 17 th century. ${ }^{3}$ We have found it rewarding to seek a history of illicit drug use in young adult patients presenting with spontaneous pneumothorax.

MARK SLADE KEITH BURGESS Department of Critical Care, Manly Hospital, Manly, NSW 2095 Australia

1 Miller WE, Spiekerman RE, Hepper NG. Pneumomediastinum resulting from performing Valsalva maneuvers during marihuana smoking. Chest 1972;62:233-4.

2 Feldman AL, Sullivan JT, Passero MA, Lewis DC. Pneumothorax in polysubstance-abusing marijuana and tobacco smokers: three cases. 7 Subst Abuse 1993;5:183-6.

3 Munsell WP. Pneumomediastinum. FAMA 1967;202:129-33.

\section{BOOK NOTICES}

Lung Cancer. Desmond N Carney. (Pp 280; £60.00). London: Arnold, 1995. 0-34056759-7.

The incidence of lung cancer has risen rapidly in recent years. The growing importance of the disease is illustrated by a great number of books on the topic. It is therefore not surprising to encounter a new book presenting state-of-the-art knowledge on lung cancer.

This book is a multiauthored work. In its 280 pages it covers numerous recent advances in our knowledge of lung cancer, is well edited, and has a pleasant uniformity of style. It is divided into two parts. The first contains chapters on chemoprevention, pathology, and staging of lung cancer. Four chapters - the best in my opinion - are focused on the treatment of the disease. The preoperative therapy and surgery, as well as the chemotherapy and radiation for lung cancer, are described in a thorough and generally well referenced fashion. There are also two well written chapters on cytokines and biological response modifiers in the treatment of lung cancer. The second part addresses the biology of the disease. In its seven chapters the latest aspects about the neuropeptide growth factors, monoclonal antibodies and molecular genetics of lung cancer are thoroughly analysed.

In general all of the chapters are well written with tables and figures and an extensive up to date bibliography. Controversial topics are well presented and the areas in which our knowledge is incomplete are indicated. The authors emphasise the need for ongoing multicentre clinical trials to resolve controversial issues. The book also provides valuable summaries of a vast amount of knowledge pertaining to virtually every aspect of lung cancer.

Because each chapter is written by a different author, there is - as in most multiauthored books - a heterogeneity in the depth at which the topics are covered; for example, very little is provided on the radiology of non-small cell lung cancer. Nevertheless, this book is well written, clearly organised, and comprehensive in scope. It is useful for anyone who is involved in the treatment and care of patients with lung cancer. - AR.

Atlas of Human Cross-Sectional Anatomy. 3rd Edition. Donald R Cahill, Matthew J Orland, Gary $M$ Miller. ( $P p$ 312; $£ 122.50)$. USA: Wiley-Liss Inc, 1995. 0471 591653.

Atlases of human anatomy have undergone a renaissance thanks to cross-sectional imaging techniques, notably computed tomography (CT) and magnetic resonance imaging (MRI), which provide an alternative view to beautiful but sometimes arcane dissections. In the third edition of this handsome atlas attention is again focused on the fine detail of line drawings of transverse sections of cadavers. At a rough estimate, there is four times as much labelling on the meticulous line drawings than on the cross-sectional photographs or MRI/CT images. Despite the fact that the CT images can no longer be regarded as state-of-the-art (as the authors acknowledge), there is more anatomical detail in these images than the labelling suggests. Perhaps this is a deliberate ploy to get readers to find out what the unlabelled bits and pieces are by looking at the line drawings. The most surprising discovery is the cursory coverage of the bronchial tree (for example, the right middle lobe bronchus does not appear in the index 'or in any illustrated section). There is no attempt to tackle the three-dimensional jigsaw puzzle of the bronchopulmonary segmental anatomy. Indeed, the CT sections of the thorax are imaged exclusively for mediastinal detail. For readers of Thorax this must be regarded as a major disadvantage; it is difficult to be impressed with rudimentary labelling that is confined to the lobes of the lungs. Overall, the treatment of the thorax is slight - 10 pages devoted to the knee versus nine pages covering the chest seems unbalanced. Nevertheless this is a fine example of an atlas that takes full advantage of crosssectional imaging and can be considered a more than adequate refresher of anatomy, particularly that outside the thorax. - DMH
Asthma and Outdoor Air Pollution. Department of Health: Committee on the Medical Effects of Air Pollutants (Pp 195; £21.00). UK: HMSO Books, 1995. $011321958 \mathrm{X}$.

Air pollution has been a hot topic in the media in the last few years and has been blamed for many respiratory problems. Doctors are often drawn into the debate by patients wishing to know if they are victims of air pollution. It has been difficult for the doctor to find reliable evidence to reply to the patient. Help is now at hand in the form of this book which reports the extensive and considered deliberations of the Committee on Medical Effects of Air Pollutants and their relationship to asthma. The book contains a wealth of information and is ordered into sections addressing relevant questions such as whether (1) there are plausible mechanisms, (2) short term exposures can worsen asthma, (3) ambient air pollution induces asthma, (4) changes in asthma prevalence correspond to changes in air pollution, and others.

Each chapter comprises a critical discussion of all the studies that address the topic and assesses what can be deduced from those studies. Each section is fully referenced and there are many helpful tables and figures. Finally, the conclusions set out what can be inferred from the present knowledge.

The committee producing this work consisted of a mix of clinicians and basic scientists with strong academic credentials which are reflected in the logical approach to the subject, the considered analysis of the evidence, and the dispassionate conclusions they have reached. Although this book is not bedtime reading, it is not difficult to read and will enable doctors and other health professionals to answer the questions posed by their patients. A copy should be in every medical library and any doctor interested in pollution will want their own copy. - MGP

\section{NOTICE}

\section{British Association for Lung Research}

The Summer Meeting of the British Association for Lung Research will be held at the Biological Sciences Building (Boldrewood), University of Southampton on 19-20 September 1996. For further information contact Mrs Chris Vincent. Telephone: 01703 796891. Fax: 01703701771

\section{CORRECTION}

In the editorial entitled "Acute lung injury following lung resection: is one lung anaesthesia to blame?" by E A Williams, T W Evans and $P$ Goldstraw which appeared on pages 114-6 of the February issue, the order of the authors should have been E A Williams, $P$ Goldstraw and T W Evans. The publishers apologise for this error. 